\title{
Reflection on the minority: phases and humanity
}

\begin{abstract}
The central problem of the article revolves concern for understanding the process of minority of the human being, in order to recognize how to reach adulthood. It shows that it is possible to identify three states: concrete, abstract and abstract I concentrate, understood as the phases of the minority toward adulthood, "Mensch" which themselves represent a human being acquires the condition expressed as art, philosophy and education as conditions that differentiates it from the animality "Tierheit" making use of rationality and linguistics. We will start then, showing that it is possible to order all stages of humanization concepts into adulthood, as utopian concept itself, conclusively, no one has fully.
\end{abstract}

Volume 4 Issue 5 - 2019

\author{
Arturo Valdivia Loro \\ Teaching researcher, National University of Callao, Peru
}

Correspondence: Arturo Valdivia Loro, Teaching researcher, National University of Callao, Peru,

Email artuo.valdivia@upn.edu.pe

Received: August 06, 2019 | Published: September 18, 2019

Keywords: life, human life, adulthood, linguistics, right

\section{Introduction}

Understand life, especially human life, is a task that involves knowing what is not and therefore would base unethical issues that end up dehumanizing those who could be considered superior or inferior compared to those found in different phases of adulthood. Axiologically, it is assumed that everything that exists has the same rights of existence ${ }^{1}$ Because no human can go back to animality but humanity depends on it. $^{3}$ Also, it is assumed that although homo sapiens reached humanity, any other animal may also have the ability to do, because if the humanization depends on the brain, hand, speech, mind, culture and society as A loop ${ }^{3}$ then there are species that currently own, albeit primitive way, but constantly evolving, and much has happened to the first product lives spontaneous creation ${ }^{4}$ to training, the pinnacle course, homo sapiens. Similarly it is considered that every person has the same rights, however, they may lose as their actions and therefore exposed to punishment as society they inhabit. Inevitably identify in practice people who have a high degree of adulthood while others, on the contrary, through their actions have little human acts that border with animality, showing a primary minority, violating the fundamental rights of others ${ }^{2}$ Ie, violating both human dignity and that of others.

It is people who are unaware of their rationality and language and in terms of Immanuel $\mathrm{Kant}^{5}$ are in a stadium minority, which they can excel when they become aware of himself as a tutor is possible to obtain dogmatism, which the adult is able to identify to discuss and avoid: "[...] I hear you cry everywhere: Do not argue! The officer says: Do not argue, adiéstrate! The Minister of Finance; Do not argue but pay! The Shepherd; Do not argue but believe! (Only one ruler in the world says: Argue all you want, but obey!)"5 An adult is aware of himself and for himself ${ }^{6}$ can be guardian of a minor as not to lose dignity in both. Education is, therefore, a fundamental tool to leave the minority ${ }^{6}$ and in turn a human and humanizing to adulthood tool. The importance of understanding life itself, human life and the process of humanization, is not to generate pseudoespeciación but in order ${ }^{1}$ Even that which he does not possess life, as may be the planet itself.

${ }^{2}$ Understood not only about other human, but anything alien to that person, that is, different to him, is to be alive or not, so it is unavoidable vigilance and punishment. $^{9}$ that humans serve as an end and not as a means ${ }^{7}$ through education, as social capital. ${ }^{8}$ To this end it is necessary to characterize the loop Morin, so, in particular, this article will focus on language understood as linguistic and mind, observed from rationality, showing scales that every human being can reach in its process to adulthood, pending the brain, hand, culture and society.

\section{Transition to adulthood: immaturity}

People, however, is a condition that can reach into adulthood. Therefore, all that being alive who has not reached such a condition is a minor and therefore require education. For Morin humanization depends on the brain, hand, speech, mind, culture and society as a loop constantly evolving. In turn, is the species homo sapiens has achieved the conditions for proclaiming themselves with mankind, however, the possibility that other species can attain such status is not closed. ${ }^{3}$ Every living thing has will, soul, mind, DNA and the conditions described above, then what becomes human to human? Namely What human than a human does not it? Art, Philosophy and Education: Three factors are proposed. ${ }^{4}$ The more developed if they are furthest from the human factors of the minority you will be, regardless of their biological development. Without going to the complexity of the discussion regarding the definition of the concepts enunciated, it is eminent that there is any other than the human being to develop a whole the three factors listed animal. Also, the adult is a being of specialization, ie self-awareness allows you to define which areas of knowledge remain a child to engage in certain areas of cognitive, artistic or educational competition. For this reason, it is not possible to determine in the history of humanity, someone who has developed all these factors together, so that in practice full adulthood does not exist, at least individually, however, if obtainable ${ }^{3}$ This statement of the discussion between differentiation, or at least attempt, between humans with other animals, for example, Fernandez-Armesto ${ }^{14} \mathrm{He}$ states that "the difference between them [chimpanzees] and us is a matter of enormous degree, but still a matter of degree", Discussing the concept of culture and society as factors that determine humanity. ${ }^{15}$

${ }^{4}$ Although this factor is no longer exclusive to homo sapiens and other species that also develops through culture, understood as the activity of transmitting or cultivate knowledge in new generations. If man educates the human being as such: Humanitas. ${ }^{16}$ Then there are species that also educate, they would be in process or evolution. 
social form, so at the level of nations, it is also possible to apply the definition of minority and adulthood, depending on the number of individuals in their complementarity have the greatest range of factors that determine the humanity.

Will, innate in all humans, can reflect and be questioned on what to specialize, so motivation is subject to a spiritual satisfaction, in principle, be extended by a material satisfaction. They are generated by both the needs ${ }^{5}$ at some point in the life of human beings where expectations of his own life is proposed and immediately begins an odyssey to reach that satisfaction, as an instinctive act to achieve fulfillment or happiness, either using the philosophy, art or education for spiritual or material purposes. Regardless of whether it is a homo sacer a videns homo, a human being conscious ${ }^{10}$ or any other type of inventory, instinct, very animal quality ${ }^{11}$ is linked to the human being distinguished according to their rationality and language will refine this purpose.

\section{Human motivations}

It will be rationalized in humans through the appearance of their needs, as weak abandons thoughts ${ }^{12}$ in order to overcome their instincts and thus feel more human or achieved in human life. About Abraham Moslow ${ }^{13} \mathrm{He}$ proposes that everyone seeks to achieve fulfill five aspects in your life: physiological needs, safety and reassurance, love and belonging, esteem and self-actualization. Thus, in parallel with its self-realization, is the motivation that drives that man has to aim at adulthood in the factor that decided to perform to achieve their full. ${ }^{6}$ However, without harming others, for which prior to each action, you must perform an act of rationality, followed by a linguistic expression.?

\section{Linguistics}

Language functions as a factor that gives humanity to life, ${ }^{20}$ Homo sapiens are born devoid of languages, however with both biological and mental corpus to apprehend him during development and serves to transmit cultura. ${ }^{8}$ Essential factor in human evolution for survival. Adulthood, the human being also depends on the domain that holds in its communication both in what Morin called first and second language, ie, the rational and emotional ${ }^{3}$ as the domain of signs.

At this point, it is important to note the distinction between basic linguistic notions: $:^{21}$

${ }^{5}$ Three appointments are highlighted about Hannah Arendt ${ }^{17}$ hen it is referring to forms of life that, by necessity, are forced to work and remain active, subject to the laws of a master. A different view would be that of John Gray, English philosopher, who affirm: "[The] 'humanity' does not exist. There are only human, driven by conflicting needs and hopes and subject to all kinds of debilitating conditions of the will and judgment". As Kant ${ }^{18}$ understands the concept as the link which would define as being possible and be effective. In all cases the need emerges as a concept used to understand humanity.

${ }^{6}$ Also, while fewer meet their needs met two possible scenarios occur: the nihilism of the weak thought that sustains Amoroso ${ }^{12}$ Which could lead to something else satisfaction to life emerging death as a solution is reached; and, on the other hand, despair ${ }^{19}$ as an attitude facing less rational and linguistic way to meet their needs, so the use of violence to the detriment of other beings emerge before the impotence.

${ }^{7}$ The fact that children acquire comparable grammars essentially highly complex and remarkable rapidity suggests that, somehow, the human being is' designed 'to do this and it has a capacity to produce data or' formulate hypotheses', whose nature and complexity are unknown. ${ }^{27}$

${ }^{81}$ Culture is a social phenomenon that has biological basis, which is transmitted from brain to brain via information and communication". ${ }^{20}$
1. Language, understood as a capacity, closely related to the evolution of the bodies involved to implement

human nature phonemes: the larynx, pharynx, mouth, lips-and why not the body itself, while there are other types that are not necessarily language-verbal. In any case, these bodies evolve in order to adequately represent thought and representation of reality that expresses the subject to communicate, so that in addition to physical appearance, or biological-also involves the rational and symbolic. Also, these capabilities are not innate homo sapiens while there are other species that share the same characteristics, ${ }^{22}$ Such as lupus familiaris canis or domestic dog, entity that has demonstrated its ability to understand the language of homo sapiens. ${ }^{23}$ In their different languages, manifesting itself not only with phonetic signs, but also physical and symbolic (for the latter may be the case when canis lupus familiaris learn to recognize the belt involves walking with homo sapiens) expressing even fullness, or misery, about. ${ }^{23}$

2. Language, considered as a system that condenses phonology (sounds), morphology (words), syntax (own

grammar), semantics (meanings) and pragmatic (symbolic or cultural meanings), contains the rules governing speech and language, however, its main contribution is the ability to interpret reality and above all, generate new words, while, through language, defined and characterized, providing social symbolism and meaning. While the language is linked more to the instinctive and the evolution of matter and life, language is a cognitive process, involving culture, for construction and learning. As if species should address, there are efforts classification, as done in principle by Friedrich Schlegel and then deepened by August Schlegel: ${ }^{24}$
a. inflected languages
b. analytical languages
c. synthetic languages
d. afijantes languages

Therefore continuing the analogy of species, languages, also evolve, however, can do so in two ways: ${ }^{24}$

a. By divergence, which is when a language is divided into others.

b. By convergence, which, in contrast to previous language about mergers.

Thus, for example, Spanish, comes from the ibero-romance, this turn of the romance languages, which, according to Stéphane Goyette $^{25}$ comes from the Vulgar Latin or sermo plebeius (plebeian speech), the Latin division in the other branch stood the refined Latin or cult, known as the sermo urbanus (urban discourse). However, the formation of Spanish is not an exclusive line of divergence, but also has evidence of convergence, especially Arabic. ${ }^{26}$

3. Speech, involves the construction and revision of the language at present study, therefore, is the element

that allows the evolution of language and also the development of new languages. Its main feature that lets you group people. It consists of messages that convey the words and sentences made according to the characteristics of the group to express it. Therefore, it is possible that the same word holds different meanings, for example, for generations or regions. One could cite the case of Peru about invasions, which 
initially were designated neighborhoods, young people and finally after human settlements, although they are substantive arguable by definition and representation of reality,

4. Language is the consequence of the evolution of language, differs from this as this is, without settling on

their background. It is the consequence of the evolutionary phenomenon of language through speech. Makes use of language to support, biological and mentally prepared to language phonetics and morphology of the talk to express ideas and thoughts.

5. Dialect, is the variability that exists in the same language. In the American case is a notable difference

between the phonemes of Colombians, Argentines, Peruvians, Chileans, Venezuelans, among others. However, it is also notable dialectic difference can be identified within a country, such as the Peruvian case presents substantial differences between the coastal region, mountains and jungle in the use of Castilian. ${ }^{28}$ However, as the Quechua dialects also differ if it's southern, central or north. Thus, it is possible to identify this group to use sign language or nonverbal communication because it is located in the language, however, does not use phonics but if morphology, syntax, semantics and pragmatics of language.

Finally, a human being with capacities of adulthood not only knows the language, but the scans, making investigations, opening the understanding of it questioning paradigms using reason detriment to a minor, who simply used without questions.

\section{The reason}

The reason, like language, has based on a system, in particular cognitive, ${ }^{29}$ which can be supported in neurobiological systems and artificial through computers. While living matter such as human base reason will be biological, Marias ${ }^{8} \mathrm{He}$ states that "all sense of reason semantic involve, in effect, three notes:

1. Reference to reality,

2. This connection and

3. Possession of it for me and myself".

So emerges a complex concept: reality. Before humans should be questioned if you have the powers to adequately perceive reality. For example, about vision, the approximate boundaries of the visible spectrum range from $400 \mathrm{~nm}$ violet to red with $700 \mathrm{~nm}$. However, this interval represents only a percentage of total known spectrum of light, regardless of what still unknown, then can we really see something and define it as the real? just as does the frequency spectrum of the sound and would that doubt, therefore, the other senses possessed by the homo sapiens, then why homo sapiens really can perceive reality? Denial would imply a probability of nihilism and say that we lived in a similar skepticism to the claims of Pyrrho of Elis ${ }^{30}$ While a statement imply the origin and construction of science. ${ }^{31}$ Opting for a pejorative of human reason about reality Liaria with a human purpose: the knowledge that, although it is limited not only by the perception that owns the species but also because is in the learning process. Our ability to perceive reality represents a tiny opening for the purposes of reason to know, understand and study reality. Perhaps because of these limitations it is that creativity emerges through the imagination or innovation as quality of reason to think that does not exist, but it is likely to be real. This feature, which represents a phase of reason, has led to a gradual advancement of knowledge. ${ }^{32}$ Not only in science but also in philosophy and technology. It has been able to achieve knowledge, for example, that the universe currently inhabiting life that recognizes humanity is not alone, but it is likely that there are many more-a multiverse, ${ }^{33}$ it has concluded that there is nothing, at least in our reality as it is the opposite to be. ${ }^{34}$ Then the human perception has not been an impediment to the approximation to the truth. It is this concept, the truth is the work of reason and in order to properly settle the truth has separated into two aspects: objective truth and subjective truth, ${ }^{35}$ Which in turn have the following contents:

1. Objective truth

a. A knowledge

i. Logic

ii. epistemologically

b. A reality

i. ontological

ii. Confidential

2. Subjective truth

a. relative

b. historical

c. utilitarian

In this regard logic as an instrument has evolved and distinguished divisions, making it possible to identify: $:^{36}$

1. Minor logic or logic of right reason.

a. Considered in relation to the rules of construction of knowledge

i. The concept 1 st operation spirit

ii. proposition 2nd operation spirit

b. Analyzed from the point of view of their formal principles

i. The reasoning 3 rd operation spirit

2. Greater logic, or logic of the real reason.

a. preliminaries

i. Considered from the point of view of the subject reasoning

1. The universal 1 st operation spirit

2. the trial 2 nd operation spirit

ii. The three instruments of knowledge

1. Definition

2. Division

3. Argumentation

b. Logic show

i. Analyzed from the point of view of its material principles $3 \mathrm{rd}$ operation spirit

1. Show false (sophistry)

2. Imperfect demonstration (probable) 


\section{The show itself (necessarily true)}

It will also be understood as a minor or formal that concerns the spirit, that is logical, it can certainly be logical, however, does not represent the real, ie not consistent, for this reason, it is the most abstract and complex logic. Meanwhile, most or materials logic is based on the propositions and deductions from it, therefore, indicates the true and false, but not necessarily correct. For there to be logical, and therefore appropriate differentiation of truth from falsehood, must possess both logical argument, noting also that the operations of spirit represent phases that reasoning must achieve.

Similarly, epistemology, which studies as a tool to knowledge, group knowledge levels: ${ }^{37}$

1. Instrumental,

2. Technical

3. methodologically

4. Technical

5. epistemic

6. gnoseológico

7. Philosophical

Similarly, you can define levels about what ontological: ${ }^{38}$

1. Of application

2. Of domain

3. basic techniques

4. Generics

Similar classification is mentioned by Smith, Kusnierczyk, Schober, \& Ceuster ${ }^{39}$ who determine ontological levels:

1. Level 1, which is the study of objects, processes, qualities, states, among others, is reality itself. If it be compared with the classification of Barry ${ }^{40}$ correspond to the formal ontology.

2. Level 2, discusses the cognitive representations of reality, ie, it lies in the domain of researchers and their relationship with others, so it relies on formal ontology, in order to make the domain ontology. ${ }^{40}$

3. Finally, Level 3, is based on the concretizations cognitive representations, level 2, for the formulation of figurative and representational artifacts. Therefore, it will link with the philosophical ontology. ${ }^{40}$

Confidential about what the objective truth of a reality, it will be understood strictly according to their progress in the field of statistics regarding the trust as a concept enunciated by Luque Rodríguez. ${ }^{35}$ Additionally, it is important to note with regard to anything that is not true, ie, fallacies, which Muñoz Gutierre $z^{41}$ It classifies them as:

\section{Formals}

2. Informales

a. Ambiguity

i. By mistake
ii. Amphibology
b. materials
i. Insufficient data
1. Generalization inadequate
2. False evidence
3. False cause
ii. Relevance
1. ad hominem
2. ad baculum
3. ad populum
4. ad verecundiam
5. ad ignorantian
6. Tu quoque

Man in order to learn, create and use properly the different skills and technologies will use his reason, this quality being the intermediary of opinion and intelligence..$^{42}$ While the opinion will make use of language for its expression, intelligence present phases that will, in turn, more complex opinion. To Bloom ${ }^{43}$ Domain categories, for intellectual development, are to remember, understand, apply, analyze, synthesize and create, the latter being the most complex. A human being will be in the minority in the less developed categories of Bloom. Additionally, it will come to adulthood in the more intelligence have been reached, in consideration of the proposed Gardner, ${ }^{44}$ Which are:

A. Academic type:
a. linguistic intelligence
b. Mathematical logic

B. Artistic type:
a. Spatial intelligence
b. Kinesthetic
c. Musical

C. Emotional type:
a. Interpersonal
b. Intrapersonal

D. Naturalistic recently added by Gardner. ${ }^{45}$

Human beings, through their biological support, also present in other species, has acquired capabilities that differentiate it with other animals, as has the ability to raise their own awareness raising its spirit, in terms of Bachelard ${ }^{46}$ and may be in three states:

A. Concrete, related to the puerile or mundane soul, which is rejoicing without question by the proven theory. It would connect with the common knowledge ${ }^{47}$ or at any rate, in inservible- knowledge. It would be a pre-scientific spirit.

B. The abstract concrete, linked to the professorial soul, which deals with the question of the theory under study, however, 
with a sensible intuition. You could link with the scientific knowledge of Bachelard ${ }^{47}$ in this case, a scientific spirit.

C. And finally, the abstract, which corresponds to the soul in the process of abstracting and fifth-esenciar in this state is discussed and evaluated doubt its veracity theory. This phase, being reflective, form a philosophical spirit.

The reason, therefore, to be present between opinion and intelligence will bridge using tools that will serve to verify the truth and discern a fallacy. Also will present limitations because without intelligence and without opinions that enunciate through linguistics will not reach the levels of Bloom, such as, for example, creation. This deficiency is noticeable in logic: "Again Report noted that the logic controls the consistency of the findings [reason] to the principles; but not always control the rise of the very principles that can give rise to a new mentality". For the same reason, there will be no intelligence without the opinion, which will serve as a communicator for your self.

However, emerges again the question: What defines the difference between an animal and a human being? As in the visible spectrum, the infrared and ultraviolet colors are denoted, then the analogy about humanity is established:

A. The-human, infra whose state will be the animal, while his kind of spirit of ignorance, so the truth is is unknown and is not intended to acquire knowledge by will, therefore, the ontological, epistemological and logic is not him of his function, however, you may briefly develop intelligence, categories and linguistic domain.

B. The ultra-human, this level of humanity, would be the most complete proposed, it is a state in which the human being has reached, and exceeded, all stages described in Table 1, and also has dignity concept emerges in any state described above, however, it is added as an additional quality to the individual reaches not only the knowledge but also the reason and linguistic excellence. While an intra-human is distópico state, the ultra-human is unrealistic case. To achieve this dignity, proper use of his secret, private and social life will be necessary.

Table I Human Scales

\begin{tabular}{|c|c|c|c|}
\hline Stadiums & Specifically State & $\begin{array}{l}\text { Been concentrated } \\
\text { abstract }\end{array}$ & Abstract state \\
\hline Kind of spirit & Prescientific & Scientific & Philosophical \\
\hline Truth about & $\begin{array}{l}\text { The truth that communicate and can } \\
\text { build fallacies or logical fallacies is not } \\
\text { questioned. }\end{array}$ & $\begin{array}{l}\text { Also reaches the truth, } \\
\text { however, especially using } \\
\text { logic and confidential. }\end{array}$ & $\begin{array}{l}\text { It questions the truth, distinguishing } \\
\text { the particular state, as, considers } \\
\text { the objective and subjective truth } \\
\text { as a means to attain knowledge. }\end{array}$ \\
\hline Ontologically & Does not use any level of Barry. & $\begin{array}{l}\text { Use the Level I and } 2 \text { of } \\
\text { Barry. }\end{array}$ & Use the three levels Barry \\
\hline As epistemic & It is instrumental and technical. & $\begin{array}{l}\text { It is instrumental, technical, } \\
\text { methodological, technical } \\
\text { and epistemic. }\end{array}$ & $\begin{array}{l}\text { It is instrumental, technical, } \\
\text { methodological, technical, epistemic, } \\
\text { epistemological and philosophical. }\end{array}$ \\
\hline In logic & Does not use major and minor logic. & $\begin{array}{l}\text { Makes use of major and } \\
\text { minor logic, however, it is } \\
\text { in a process to achieve the } \\
\text { three operations of the } \\
\text { mind. }\end{array}$ & $\begin{array}{l}\text { Lives immersed using the three } \\
\text { operations of the mind. }\end{array}$ \\
\hline $\begin{array}{l}\text { As for the } \\
\text { intelligences }\end{array}$ & $\begin{array}{l}\text { He is unaware of intelligences who owns } \\
\text { or failing that, considered as strictly } \\
\text { academic intelligence. }\end{array}$ & $\begin{array}{l}\text { He is aware of the } \\
\text { intelligence that owns and } \\
\text { seeks its acquisition and } \\
\text { practice, however, prevail in } \\
\text { some category: academic, } \\
\text { artistic, emotional or } \\
\text { natural. }\end{array}$ & $\begin{array}{l}\text { It is based on the constant } \\
\text { reflection on each intelligence and } \\
\text { practice each. }\end{array}$ \\
\hline $\begin{array}{l}\text { Domain categories } \\
\text { Bloom }\end{array}$ & $\begin{array}{l}\text { You may only use categories to } \\
\text { remember, understand and apply. }\end{array}$ & $\begin{array}{l}\text { You can use all categories } \\
\text { of Bloom. }\end{array}$ & You can use all categories of Bloom. \\
\hline About linguistics & $\begin{array}{l}\text { Unaware of linguistics, however, makes } \\
\text { use of some components, such as speech } \\
\text { and dialect. It also has the biological } \\
\text { support of language. }\end{array}$ & $\begin{array}{l}\text { Knows and uses the } \\
\text { language. }\end{array}$ & $\begin{array}{l}\text { Know, investigates, questions and } \\
\text { use language. }\end{array}$ \\
\hline
\end{tabular}


Therefore, the process towards humanization has three categories: animality, humanisation and humanity. The matter is unique in achieving these states through evolution, however, may reverse the arrow of time advances, devolving, for example, human, animalizing, ie, losing his humanity. By contrast, a baby grows not only homo sapiens, but develops dignificándose and raising their stadiums to reach, if possible, the utopian state of humanity, i.e exist as a human being integrity. With this statement, the possibility that any species other than homo sapiens, can achieve a process of humanization is also opening, although the name of this process is related to the human being.

\section{Conclusion scales minority}

The journey to adulthood, is certainly utopian. There are still human beings who have developed full capabilities in parallel on all factors: art, philosophy and education, as we always have to sacrifice some of these issues because of their need for self-motivates him to specialize in what gives you greater spiritual satisfaction, in principle. Therefore, there is an adult in full and will always be a certain field where it remains in minority. Also, the human condition is an achievable state as some species can get the minority. Homo sapiens because its evolution is born with biological support to reach adulthood and minor born, so human is born and never loses that category, ${ }^{3}$ Ie, you can not return to an animal state, although it depends on his humanity. To achieve humanity, it must be achieved through development of language and reason, components that are shared with other species, however they are used to achieve individual and social will. The minority has characteristics that make it up: Type spirit, levels of truth, the ontological, epistemological, logic, intelligence, domain categories Bloom, who make up the group of reason, which is added linguistics. Every human being will go through all these phases to improve, or autorealizandose because of his will for their material and spiritual, to reach their fulfillment with dignity in respect of all other beings beyond their humanity. ${ }^{48-50}$

\section{Acknowledgments}

None.

\section{Funding}

Nill.

\section{Conflicts of interest}

Author declares that there is no conflict of interest.

\section{References}

1. Heidegger M. Being and Time. Santiago de Chile, Chile: Universitaria; 1997.

2. Muñoz Pérez E. Human, animal and animality be. Novelty and scope of the fundamental concepts of metaphysics. World, Finitud, loneliness 1929-1930 Martin Heidegger. Veritas. 2013;29:77-96.

3. Morin E. The method. E Morin, humanity of mankind. Human identity. Vol V. Spain: Madrid, Chair; 2003.

4. Pasteur L. Spontaneous generation. In: G Diaz DOiN, editor. Cours des sicentifiques Revue. Buenos Aires: Emecé; 1944/1863-1864. p. 257-265.

5. Kant I. Answer to the question what is the picture? 1986/1784;3(14-17):7-10.
6. Marx K. Poverty of Philosophy. Response to the philosophy of the misery of PJ Proudhon. Argentina: Buernos Aires, Siglo XXI. 1987.

7. Kant I. Groundwork of the Metaphysics of Morals 1st ed. In: P Rosario Barbosa, editor. San Juan: Puerto Rico; 1923.

8. March C. Dignity for all. Argentina: Buenos Aires, Issues publishing group; 2009.

9. Foucault M. Watch out and punish. Argentina: Buenos Aires, Argentina veintinuo century editors; 2002.

10. Holzapfel C. Ser-human (anthropological Mapping). Chile: Remarks Philosophical Magazine; 2010.

11. Laplanche J. Impulse and instinct. Alter. Psychoanalysis magazine. 2014;1:1-12.

12. Amoroso L. The Lightung Heidegger as locus (non) lucendo. In: G Vattimo, PA \& Rovatti, editors. Madrid, Spain: Chair; 2006. p. 192-228.

13. Maslow A. A theory of human motivation. Psychological Review. 1943;50(4):370-396.

14. Fernandez-Armesto F. I então você que é pensa human? Uma da humanidade brief history. São Paulo: Cia das Letras; 2007.

15. Barbosa de Magalhães V. The concept of humanity in the social sciences. Magazine Society and Economy. 2009;17:215-228.

16. Megale Altieri A. ¿Qué es la cultura? 2001;2(4):15-20.

17. Arendt H. The human condition. Argentina: Buenos Aires, Paidos; 2009.

18. Kant I. Critique of Pure Reason. Spain: Madrid, Taurus; 2010.

19. Cioran E. On the tops of despair. Spain: Barcelona; 1996.

20. Silva Santisteban F. The primate responsible. Anthropobiology behavior. Lima: Editorial Fund of the Peruvian Congress; 2005.

21. Finch Daza SL. Basic language concepts: Language, language, speech, idiomay dialect. The Thaddeus. 2005;71:9-21.

22. Aitchinson J. The articulate mammal: Introduction to psycholinguistics. Spain: Madrid, Alianza Editorial; 1992.

23. McConnell P. For the Love of a Dog: Understanding Emotion in You and Your Best Friend. NY: Ballantine Books; 2007.

24. Alonso-Cortes. Linguistics. Spain: Madrid, Chair; 2008.

25. Goyette S. The emergence of Romance Languages from Latin: A case for creolization effects. Doctoral thesis post, Ottawa: University of Ottawa; 2000 .

26. Current F. A Grammatical Sketch of the Spanish Arabic Dialect Bundle. Spain: Madrid, Instituto Hispano-Arab cultura; 1977.

27. Chomsky N. Critical review of Berval behavior of BF Skinner. Convivium. 1973;38:66-105.

28. Escobar A. Sociolinguistic variations of Castilian in Peru. Peru: Lima, IEP editions; 1978.

29. Morris R, Tarassenko L, Kenward M. Cognitive Systems-Information Processing Meets Brain Science. California: San Diego, Elsevier Academic Press; 2006.

30. Pajón Leyva I. Pirrónico categories and assumptions of skepticism. Madrid: PhD thesis, University Complutense de Madrid; 2001.

31. Cañedo Andalia R. Brief history of the development of science. ACIMED 1996;4(3):38-41.

32. Garcia M, Matković L. The power of imagination and creativity to science. Live Chemistry. 2012;11(1):54-68. 
33. Barrau A, Gyger P, Kistler M. Multivers mondes possibles de l'astrophysique, the philosophie et de l'imaginaire. Montreuil, France: La ville brule; 2010.

34. Viudes Alarcon VM. Philosophy of reality: A Parte Rei. Philosophy magazine. 2004;33:1-3.

35. Luque Rodriguez J. Knowledge. Seville, Spain: Universidad de Sevilla 1993.

36. Maritain J. The order of the formal-logic concepts. Argentina: Buenos Aires, Book Club; 1975.

37. González Sánchez J. The community of knowledge: elements for building a model of academic management at the high school level and upper level. Mexico: Plaza y Valdez; 1997.

38. Sanchez Lopez SE. Indexing model forms VIR systems based on ontologies. Puebla: Universidad de las Américas Puebla; 2007.

39. Smith B, Kusnierczyk W, Schober D, et al. Towards a Reference Terminology for Ontology Research and Development in the Biomedical Domain. KR-MED. 2006;222:57-65.

40. Barry S. Beyond Concepts: Ontology as Reality Representation. In: A Varzi, L vieu, editors. Formal Ontology and Information Systems. Turin, Italy: IOS Press; 2004.

41. Muñoz Gutierrez C. Introduction to Logic. Spain: Madrid, Universidad Complutense de Madrid; 2014
42. Plato. Republic. Spain: Madrid, Gredos; 1988.

43. Ferraz Marcheti do Carmo AP, Vairo Belhot R. Bloom's Taxonomy: theoretical and apresentação revisão das adequações do definição instrument of instrucionais goals. Gest Prod. 2010;17(2):421-431.

44. Gardner H. Frames of Mind: The Theory of multiple intelligences. NY: Basic; 1983.

45. Gardner H. Reformulated intelligence: multiple intelligences in the XXI century. Spain: Barcelona, Polity Press; 2001.

46. Bachelard G. The formation of the scientific spirit. Mexico: Twenty-First Century; 2000.

47. Bachelard G. Common knowledge and scientific knowledge. Argentina: Buenos Aires, Polity Press; 1978.

48. Give W. Reason and intelligence. Genova, Italy: Studio Editoriale di cultura; 1984

49. Gray J. Cubs palha: reflexões human and outros animais. Brazil: São Paulo, Record; 2007.

50. Maries J. The reason in today's philosophy. Proceedings of the First National Congress of Philosophy. Argentina: National University of Cuyo; 1949. p. 936-942. 